OPEN ACCESS

Edited by:

Ke Chen,

Woods Hole Oceanographic

Institution, United States

Reviewed by:

Mariana Mayer Pinto,

University of New South Wales,

Australia

Danielle Denley,

Dalhousie University, Canada

${ }^{*}$ Correspondence:

Heidi L. Burdet

h.burdett@hw.ac.uk

Specialty section:

This article was submitted to Marine Ecosystem Ecology,

a section of the journal

Frontiers in Marine Science

Received: 15 February 2019

Accepted: 06 August 2019

Published: 27 August 2019

Citation:

Burdett HL, Wright $H$ and Smale DA (2019) Photophysiological Responses of Canopy-Forming Kelp

Species to Short-Term Acute

Warming. Front. Mar. Sci. 6:516.

doi: 10.3389/fmars.2019.00516

\section{Photophysiological Responses of Canopy-Forming Kelp Species to Short-Term Acute Warming}

\author{
Heidi L. Burdett ${ }^{1,2 *}$, Honor Wright ${ }^{2}$ and Dan A. Smale ${ }^{3}$ \\ ${ }^{1}$ Lyell Centre for Earth and Marine Science and Technology, Edinburgh, United Kingdom, ${ }^{2}$ School of Energy, Geoscience, \\ Infrastructure and Society, Heriot Watt University, Edinburgh, United Kingdom, ${ }^{3}$ Marine Biological Association of the \\ United Kingdom, Plymouth, United Kingdom
}

The frequency of short-term oceanic warming events ["marine heatwaves" (MHWs) or heat spikes] has increased over the past century and is projected to further increase because of anthropogenic climate change. Given that marine organisms are strongly influenced by temperature, an increased occurrence of warming events could alter the structure of populations, communities, and ecosystems. The distribution and ecophysiological performance of kelp species - globally important foundation species that play significant roles in nutrient cycling and habitat creation in temperate coastal systems - is particularly constrained by temperature. However, their photophysiological responses to warming events remains unclear, which hinders attempts to understand, and predict the effects of ocean warming on kelp populations and the ecosystems they underpin. Here, we experimentally simulated a heat spike $\left(+2^{\circ} \mathrm{C}\right.$ and $+4^{\circ} \mathrm{C}$ in magnitude, 3 days in duration, and compared with ambient controls) and examined the photophysiological responses of two canopy-forming kelp species widely distributed across the northeast Atlantic - Laminaria digitata and Laminaria hyperborea. Both species were resilient to the realistic warming treatments in terms of their photosynthetic characteristics. However, we found that $L$. digitata individuals, which were collected from populations found toward the upper limit of this species' thermal range, exhibited increased oxygen production at higher temperatures, particularly after multiple days of exposure to the warming event. L. digitata also exhibited a greater poise for dissipating excess energy through non-photochemical pathways. In contrast, L. hyperborea, which extends further south into warmer waters and tends to occupy deeper reefs that are almost constantly submerged, appeared to be photo-physiologically insensitive to the heat spike. This study enhances our mechanistic understanding of the photophysiological and photoprotective responses of kelps to short-term acute warming events - features which are likely to emerge as important drivers of ecological change in coming decades.

Keywords: kelp, photophysiology, PAM fluorescence, marine heatwave, Laminaria digitata, Laminaria hyperborea, macroalgae 


\section{INTRODUCTION}

The upper layers of the global ocean have warmed at a rate of $\sim 0.1^{\circ} \mathrm{C}$ per decade since the mid-20th century, albeit with pronounced regional, and seasonal variability (IPCC, 2013). Recent climatic changes have caused changes in the distribution of species (Pinsky et al., 2013; Poloczanska et al., 2013), the structure of communities and ecosystems (Vergés et al., 2014; Wernberg et al., 2016), and the provision of ecosystem services (Pecl et al., 2017). Superimposed onto gradual warming trends are discrete extreme warming events "marine heatwaves" [MHWs] or "heat spikes" - during which sea temperatures are anomalously high for periods of days to months or even years (Hobday et al., 2016, 2018). Recent research has shown that over the past century MHW frequency and duration increased by 34 and 17\%, respectively, and that many regions have experienced rapid intensification of MHWs (Oliver et al., 2018). Moreover, it is likely that MHWs will intensify in coming decades, as a result of anthropogenic climate change (Frölicher et al., 2018). As the distribution of marine species is highly constrained by temperature, with many populations persisting toward the upper limits of species' thermal niches (Sunday et al., 2012), continuation of both long- and short-term warming will drive redistribution of species, and reconfiguration of communities and ecosystems at the global scale (García Molinos et al., 2016; Hughes et al., 2017).

Kelps (macroalgae of the Order Laminariales) are distributed along approximately one-quarter of the world's coastlines, across temperate and subpolar latitudes in both hemispheres, where they function as foundation species in nearshore marine ecosystems (Steneck and Johnson, 2013; Teagle et al., 2017). By providing complex biogenic habitat and exhibiting high rates of primary productivity, kelps enhance local biodiversity, fuel inshore food webs, and elevate secondary productivity (Steneck et al., 2002; Teagle et al., 2017, 2018). With regards to inshore carbon cycling, kelps fix and transfer globally significant amounts of carbon (Krause-Jensen and Duarte, 2016) that may eventually become trapped and stored in sediments, and thus contribute toward natural carbon sequestration (KrauseJensen and Duarte, 2016; Smale et al., 2018). However, the ecophysiology and spatial distribution of kelp species is strongly influenced by temperature (Eggert, 2012); recent ocean warming trends have been linked with major shifts in the structure and functioning of some kelp populations and their associated communities (Wernberg et al., 2016). Increased temperature may also impact rates of primary productivity and carbon assimilation and transfer, with knock-on effects for interconnected habitats (Pessarrodona et al., 2019). That said, a recent global analysis (Krumhansl et al., 2016) showed that temporal trends in kelp populations are highly variable between different species and biogeographical regions. Whilst there is a general consensus that continued ocean warming will drive shifts in the geographical ranges of kelp species and changes in kelp-dominated communities (Harley et al., 2012; Brodie et al., 2014), the underlying physiological mechanisms and the drivers of observed variability in contemporary responses are poorly understood.

Kelps are distributed along rocky coastlines throughout the NE Atlantic from Portugal and Morocco to northern Norway and Iceland (Bolton, 2010). Multiple kelp species are found within this region, each with varying environmental requirements, so that different species persist and dominate under different environmental conditions (Smale et al., 2013). Recent warming trends have driven some shifts in kelp distributions, with coolaffinity species declining at their warm trailing range edge (Raybaud et al., 2013; Tuya et al., 2014) and warm-affinity species expanding at their cool leading range edge (Smale et al., 2015), resulting in changes in local diversity (Teagle and Smale, 2018), and ecosystem functioning (Pessarrodona et al., 2019). Conversely, some kelp populations have remained relatively constant and stable over time (Krumhansl et al., 2016). At the physiological level, the temperature range within which kelps can carry out critical processes such as photosynthesis varies between species, life stages and the processes themselves (Delebecq et al., 2016), so that determining the thermal niche is complex. Even so, the extreme temperatures that macroalgal populations are exposed to during MHWs can exceed thermal thresholds, inducing protective responses (e.g., heat shock proteins, see King et al., 2019) and leading to impaired performance (Hargrave et al., 2017), altered physiology (Gouvêa et al., 2017), and ultimate mortality (Wernberg et al., 2013). Inter-specific variability in photophysiological mechanistic responses to short-term acute warming events remains unclear, but would allow for improved predictions of the future effects of ocean warming on kelp populations and the communities they underpin.

Here, we examined photosynthetic characteristics (as net oxygen flux in the light and chlorophyll-a fluorescence) of two critical habitat-forming kelp species - Laminaria digitata and Laminaria hyperborea - during a short-term acute warming event. These kelp species dominate wave exposed rocky reef habitats along much of the NE Atlantic coastline. Both species have a northern Boreal distribution: L. hyperborea is distributed from the Arctic to northern Portugal while $L$. digitata is distributed from the Arctic to a southerly range limit in northern France in the NE Atlantic. The current warm water limit of $L$. digitata is $\sim 100$ nautical miles south of the location of the current study; range edge populations are subjected to a similar climatic environment as those examined here. As well as differences in latitudinal ranges, these species differ in their vertical distributions as L. digitata is primarily found in the low intertidal zone whereas L. hyperborea tends to dominate deeper reefs, extending from the extreme low intertidal to subtidal reefs. Differences in latitudinal extensions and vertical distributions may manifest in differing responses to contemporary and predicted future ocean warming, although previous experimental work suggests they have similar upper thermal tolerances (Bolton and Lüning, 1982; tom Dieck, 1993). The aim of this study was to determine photophysiological responses of populations of these ecologically important species to short-term warming events. 


\section{MATERIALS AND METHODS}

\section{Experimental Set-Up}

Both Laminaria digitata and L. hyperborea were collected by removing whole plants from their in situ environment; individuals were carefully removed by prising the holdfast from the rocky substratum. Both species were collected from within Plymouth Sound - L. digitata was collected from the shore during a low spring tide and $L$. hyperborea was collected by SCUBA divers at $\sim 1 \mathrm{~m}$ depth (BCD). In total, 24 mature, medium sized (stipe length $30-50 \mathrm{~cm}$ ) individuals of each species were collected, stored in seawater containers and immediately returned to the laboratory. The experiment described below was first conducted with $L$. digitata and subsequently with $L$. hyperborea using exactly the same approach. Kelp specimens were collected immediately prior to their respective experiment so the length of time between field collection and the start of the experiment was the same for both species. All experimentation was completed during a 16-day period in July 2017.

During each experiment, two plants were placed into each of 12 individual $130 \mathrm{~L}$ tanks filled with local filtered seawater within a recirculating system. Plants were orientated in an upright position by securing holdfasts to rocks using cable ties; duplicate plants were placed at opposite ends of the tanks, $\sim 50 \mathrm{~cm}$ apart, to simulate actual densities recorded in the field (e.g., Smale et al., 2016; Hereward et al., 2018). Two plants were placed in each tank to reflect natural populations (i.e., plants are generally found in stands rather than individually) and to capture between-plant variability. Seawater was maintained at the desired temperature (see below) with aquarium chillers (DC750, Deltec, Delmenhorst) or heaters (300W DR-9300, Boyu, Guangdong) as necessary. Turbulent water flow was generated with a wave maker in each tank (WM-6000, All Pond Solutions, Uxbridge). Salinity was maintained at 35 with the addition of fresh water as necessary. Lamps specifically designed for aquatic plants (Reef Daylight T8 36 W, Interpret, Dorking) were used to generate a 14:10 h light-dark regime with PAR irradiance levels of $\sim 100 \mu \mathrm{mol} \mathrm{m} \mathrm{m}^{-2}$ (recorded with an Odyssey PAR meter). Average daily light intensity (measured with a Hobo pendant logger, 15 min intervals, daytime only) during the experiment was $1970 \pm 163$ Lux. As such, levels of PAR and light intensity, as well as the daylight regime used in the study were comparable to those experienced by natural populations in situ during typical summer months (Pedersen et al., 2014; Smale et al., 2016).

Plants were held at ambient water temperature for $60 \mathrm{~h}$ to acclimate to tank conditions. Ambient temperature was set at $\sim 16^{\circ} \mathrm{C}$, which is typical of local summer sea temperatures from the surface to $>20 \mathrm{~m}$ depth - well within the depth ranges inhabited by the study species (Smyth et al., 2009; Brewin et al., 2017). Following this, the water temperature of four replicate tanks was gradually increased by $\sim 2^{\circ} \mathrm{C}$ over a 48 -h period. The water temperature of four other replicate tanks was increased over the same 48 -h period by $\sim 4^{\circ} \mathrm{C}$. The water temperature of the remaining four tanks was maintained at ambient temperature. These temperature treatments were selected as they are representative of the magnitude of actual warming events, both generally (Hobday et al., 2016) and specifically within the study location (Joint and Smale, 2017). Each set of four tanks were fed by a larger header reservoir, so that water temperature in each tank within each treatment was consistent. Water changes were conducted daily $(\sim 10 \%$ of total volume) using local filtered seawater. Experimental temperatures were maintained for a further 3 days to simulate short-term acute warming events of differing magnitude (i.e., $\sim+2^{\circ} \mathrm{C}$ and $\sim+4^{\circ} \mathrm{C}$ ); the temperature treatments of ambient conditions, low magnitude and high magnitude warming are hereafter referred to as $T_{0}, T_{1}$, and $T_{2}$, respectively (Supplementary Figure S1). Temperature was monitored in each set of tanks using Hobo pendant loggers, which recorded temperature every 15 min throughout the experiment. Net daytime oxygen flux was measured on days 1-3 of the heat spike period, whilst photosynthetic characteristics were measured on days one and two only (analytical details below).

\section{Net Oxygen Flux}

Net $\mathrm{O}_{2}$ flux from kelp individuals was measured using unstirred benthic chambers placed over the basal meristematic area of the blade, which were weighed down to avoid movement during the incubation $\left(270 \mathrm{ml}\right.$ volume, $95 \mathrm{~cm}^{2}$ surface area, and transparent to incoming PAR). At the start of the incubation, the oxygen concentration of the water inside the chamber was measured using an oxygen optode system (PreSens Fibox 3), with optode sensor spots fixed to the inside chamber wall. Incubations lasted for $\sim 2 \mathrm{~h}$ (exact time noted for each incubation), following which a second $\mathrm{O}_{2}$ concentration measurement was made. Net change in $\mathrm{O}_{2}$ concentration from the start to the end of the incubation was used to determine the net $\mathrm{O}_{2}$ flux between the kelp frond and the overlying water column (i.e., net increase in $\mathrm{O}_{2}$ concentration over time $=$ net $\mathrm{O}_{2}$ production by the kelp). Net $\mathrm{O}_{2}$ flux of each plant within each tank was measured on days 1, 2, and 3 of the warming treatments at the same time of day for each sample.

\section{Photophysiological Responses}

Chlorophyll-a fluorescence measurements were conducted using Pulse Amplitude Modulation fluorometry, with a Diving-PAM instrument (Walz $\mathrm{GmbH}$ ) and used to calculate photosynthetic characteristics of the kelp plants. Measurements were taken following previous methodologies and notations (Burdett et al., 2012, 2014). Notation and parameter calculations are provided in Supplementary Table S1. A 5-mm-diameter fiber optic probe was used for all measurements, positioned $10 \mathrm{~mm}$ from the surface of the kelp plant. Quasi-dark acclimation (Hennige et al., 2008) was achieved by using the "Surface holder" Walz accessory and placing this over the kelp plant for $10 \mathrm{~s}$ prior to taking rapid light curve (RLC) measurements - this is known to be sufficient time to achieve results statistically similar to full dark acclimation in a range of marine photosynthetic organisms (Hennige et al., 2008; Burdett et al., 2012). PAM settings were: measuring light intensity $=3$, damping $=3$, gain $=8$, saturation pulse intensity $=2$, saturation pulse width $=1.0$, and actinic light intensity $=1$.

Rapid light curves, where organisms are exposed to pulses of saturating actinic light interspersed with short periods of 
increasing levels of irradiance, were conducted on both the basal (meristematic) area and distal ("old" growth) area of the blade. Measurements were obtained (at approximately the same time of day) from each plant on days 1 and 2 of the warming. RLCs have become well established within PAM fluorometry and provide information on energy dissipation from light-limiting through to light-saturating conditions (Ralph and Gademann, 2005). However, due to the short exposure time at each irradiance step, steady-state conditions are not achieved (Ralph and Gademann, 2005). Thus, in contrast to traditional light curves, results from RLCs reflect actual, rather than optimal, photosynthetic state (Ralph and Gademann, 2005), yielding data on dark/lightacclimated minimum fluorescence $\left(F_{\mathrm{o}}\right.$ and $F_{\mathrm{o}}{ }^{\prime}$, respectively), dark/light acclimated maximum fluorescence $\left(F_{\mathrm{m}}\right.$ and $F_{\mathrm{m}}$ ', respectively), fluorescence under actinic light $\left(F^{\prime}\right)$, and quenched fluorescence $\left[F_{\mathrm{q}}{ }^{\prime}\right.$, defined as $\left.\left(F_{\mathrm{m}}-F^{\prime}\right)\right]$. In this experiment, the RLCs used eight irradiance steps each of $10 \mathrm{~s}$ duration ranging from 1 to $569 \mu$ mol photons $\mathrm{m}^{-2} \mathrm{~s}^{-1}$.

Maximum photosynthetic efficiency, $F_{\mathrm{v}} / F_{\mathrm{m}}$, was defined as $\left(F_{\mathrm{m}}-F_{\mathrm{o}}\right) / F_{\mathrm{m}}$. The minimum saturating intensity $\left(E_{\mathrm{k}}\right.$ - the irradiance level at which light shifts from being photosynthetically limiting to photosynthetically saturating; units $=\mu$ mol photons $\mathrm{m}^{-2} \mathrm{~s}^{-1}$ ) and initial photosynthetic rate [alpha $(\alpha)$; no units] were calculated by fitting RLC data to the irradiance-normalized non-linear least squares regression model of Jassby and Platt (1976) in the R package Phytotools (Silsbe and Malkin, 2015) to describe the light response of quantum efficiency using the following equation:

$$
y=(1 / x) * \alpha * E_{\mathrm{k}} * \tanh \left(x / E_{\mathrm{k}}\right)
$$

Where $x=$ PAR levels of each RLC step and $y=F_{\mathrm{q}}{ }^{\prime} / F_{\mathrm{m}}{ }^{\prime}$ at each RLC step. All model fits were statistically significant (model $p$-value $<0.0001$ for all). Maximum relative electron transport rate $\left(r \mathrm{ETR}_{\max }\right)$ was calculated as $E_{\mathrm{k}}{ }^{*} \alpha$. Effective photochemical efficiency under actinic light $\left(F_{\mathrm{q}}{ }^{\prime} / F_{\mathrm{m}}{ }^{\prime}\right)$ was defined as $F_{\mathrm{q}}{ }^{\prime} / F_{\mathrm{m}}{ }^{\prime}=\left(F_{\mathrm{m}}-F^{\prime}\right) / F_{\mathrm{m}}{ }^{\prime}$. Quasi-non-photochemical quenching (NPQ) was defined as NPQ $=F_{\mathrm{m}}-F_{\mathrm{m}}{ }^{\prime} / F_{\mathrm{m}}{ }^{\prime}$ (Bilger and Björkman, 1990) under peak RLC irradiance. A second non-photochemical quenching parameter $(\mathrm{qN})$ is defined as $\mathrm{qN}=F_{\mathrm{v}}{ }^{\prime} / F_{\mathrm{m}}{ }^{\prime}$ at each RLC step. Photochemical quenching $(\mathrm{qP})$ is defined as $\mathrm{qP}=F_{\mathrm{q}}{ }^{\prime} / F_{\mathrm{v}}{ }^{\prime}$ at each $\mathrm{RLC}$ step. $F_{\mathrm{q}}{ }^{\prime} / F_{\mathrm{m}}{ }^{\prime}$, $\mathrm{NPQ}, \mathrm{qN}$, and $\mathrm{qP}$ were expressed against $\mathrm{E} / E_{\mathrm{k}}$ (where $\mathrm{E}=\mathrm{RLC}$ light level) to assess sample response relative to limiting/optimal/saturating irradiance for photosynthesis when $\mathrm{E} / E_{\mathrm{k}}<1 /=1 />1$, respectively.

\section{Statistical Analysis}

Duplicate plants within each tank were treated as subsamples and response variable measurements were averaged across plants to yield a single value per tank; all analyses were conducted with tanks as true replicates. Repeated measure analysis of variance was conducted to examine the effects of temperature treatment (3 levels, fixed), tank (repeated, nested within temperature), and experimental day (3 levels, fixed) on net oxygen production. As each species was experimented on separately in serial manipulations, data on each was analyzed separately and informal comparisons across species were made. Data were first tested for normality and homogeneity of variance and transformed were necessary. Where significant main effects or interactions were detected (at $p<0.05$ ), further pairwise tests (SNK) were conducted to explore further. A similar approach was adopted to examine variability in photophysiological response variables. Data from the basal and distal sections of the blade were analyzed separately using a model similar to that described above: temperature treatment (3 levels, fixed), tank (repeated, nested within temperature), and experimental day (2 levels, fixed).

\section{RESULTS}

\section{Experimental Conditions of the Simulated Heat Spike}

During the first experiment, on L. digitata, daily mean temperatures in the treatments during the 3-day warming event were: $T_{0}=15.7 \pm 0.1^{\circ} \mathrm{C}, T_{1}=18.4 \pm 0.0^{\circ} \mathrm{C}$, and $T_{2}=19.9 \pm 0.0^{\circ} \mathrm{C}$, which corresponded to ambient conditions, $+2.7^{\circ} \mathrm{C}$ and $+4.2^{\circ} \mathrm{C}$ treatments, respectively. In the second experiment, on $L$. hyperborea, daily mean temperatures in the three treatments were: $T_{0}=15.6 \pm 0.1^{\circ} \mathrm{C}, T_{1}=18.3 \pm 0.1^{\circ} \mathrm{C}$, and $T_{2}=20.1 \pm 0.1^{\circ} \mathrm{C}$, corresponding to ambient conditions, $+2.7^{\circ} \mathrm{C}$ and $4.5^{\circ} \mathrm{C}$, respectively (Supplementary Figure $\mathbf{S 1}$ ).

\section{Net Oxygen Flux}

For Laminaria digitata, $\mathrm{O}_{2}$ production tended to increase with increased temperature and with experimental day (Figure 1). By the third day, net $\mathrm{O}_{2}$ flux was more than four times greater in the $T_{2}$ treatments compared with $T_{0}$ (Figure 1). The effect of temperature was statistically significant: pairwise tests showed that $\mathrm{O}_{2}$ production was greater at $T_{2}$ compared with $T_{0}$ and $T_{1}$ (Table 1). Duration of exposure was also important, as $\mathrm{O}_{2}$ production was greater on experimental Day 3 compared with Day 1 (Table 1). For L. hyperborea, the effect of warming on $\mathrm{O}_{2}$ production was less evident, with no consistent responses to either temperature treatment or experimental day (Figure 1). Statistically, the interaction term between the main factors was significant (Table 1), with pairwise tests indicating that the effect of temperature treatment was significant on Day 1, but not on Day 2 and 3. By Day 3 of the warming, no differences in net $\mathrm{O}_{2}$ production between treatments were recorded (Table 1). Informal comparison between the species indicated that $\mathrm{O}_{2}$ production rates for $L$. digitata were generally greater than L. hyperborea, particularly under the higher warming treatments (Figure 1).

\section{Photophysiological Responses}

For Laminaria digitata, photosynthetic efficiency $\left(F_{\mathrm{v}} / F_{\mathrm{m}}\right)$ values were relatively consistent between factors, with mean values ranging from $\sim 0.72$ to $\sim 0.74$ (Figure 2 ). For basal blade tissue, we recorded a significant effect of experimental day as $F_{\mathrm{v}} / F_{\mathrm{m}}$ values were lower, overall, on Day 2 (Table 2). For distal blade tissue, no significant variability was detected (Table 2). For L. hyperborea, mean $F_{\mathrm{v}} / F_{\mathrm{m}}$ was higher, ranging from $\sim 0.74$ 


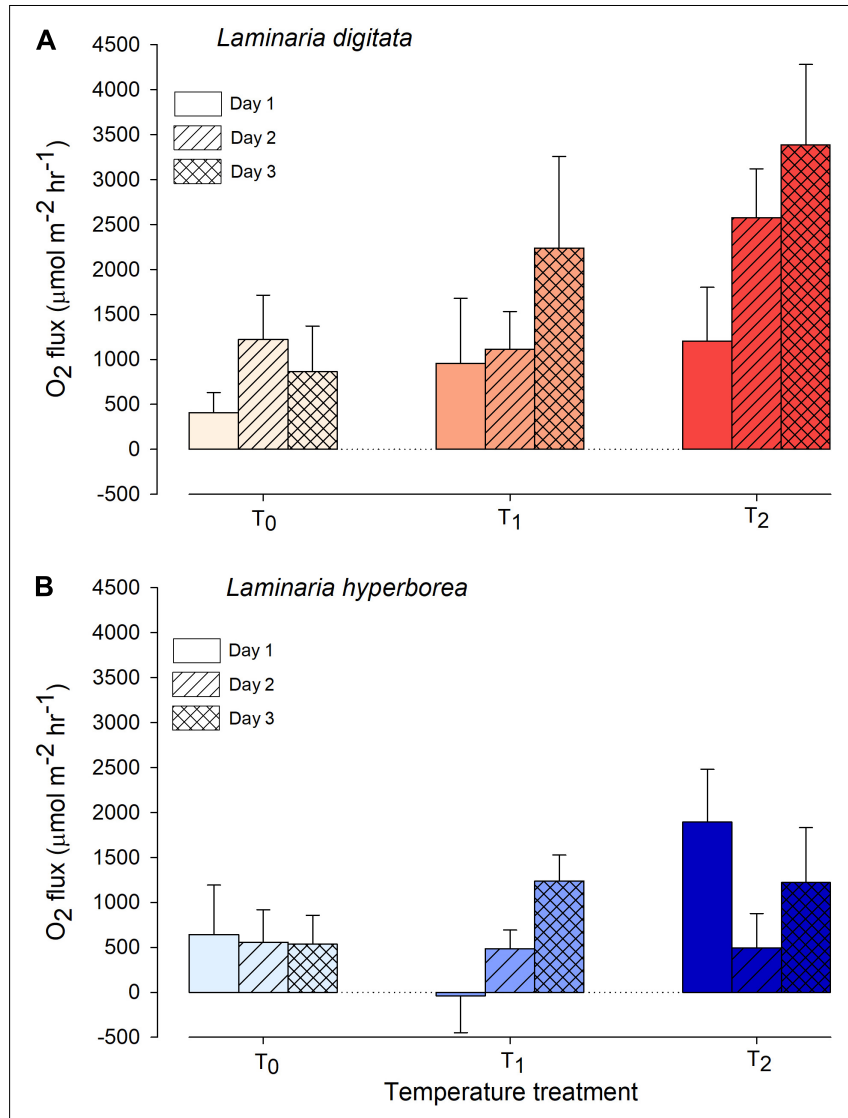

FIGURE 1 | Net daytime $\mathrm{O}_{2}$ flux from (A) Laminaria digitata and (B) Laminaria hyperborea at each temperature treatment during a 3-day simulated heat spike. Data presented as mean $\pm \mathrm{SE}$ ( $n=4$ individual aquaria per treatment).

to 0.76 (Figure 2). For both basal and distal blade tissue, no significant effects of time or temperature were recorded (Table 2). Overall, $F_{\mathrm{v}} / F_{\mathrm{m}}$ values were slightly lower for L. digitata compared with $L$. hyperborea (Figure 2). A similar pattern was observed for alpha $(\alpha)$, a measure of initial photosynthetic rate, in that the basal blade tissue of L. digitata exhibited the greatest response, with a general decline in $\alpha$ with increasing temperature and significantly lower values on Day 2 of experimentation (Supplementary Table S2 and Supplementary Figure S2).
For Laminaria digitata, saturation intensity $\left(E_{\mathrm{k}}\right)$ measured on basal blade tissue varied markedly between experimental days, with overall values on Day 2 being significantly higher than on Day 1 (Figure 3 and Table 2). There was a general increase in $E_{\mathrm{k}}$ with increasing temperature treatment, although betweensample variability meant that this trend was not significant. For distal blade tissue, $E_{\mathrm{k}}$ values were relatively consistent between temperature treatments and days (Figure 3). For L. hyperborea, $E_{\mathrm{k}}$ values measured in basal blade tissue were relatively consistent across treatments and days, and no significant effects were detected (Figure 3 and Table 2). In contrast, $E_{\mathrm{k}}$ values measured in distal blade tissue varied markedly between days, with overall values on Day 2 being significantly lower than on Day 1 (Figure 3 and Table 2). A similar pattern was observed for maximum relative electron transport rate $\left(\mathrm{rETR}_{\max }\right.$; Supplementary Table S2 and Supplementary Figure S3).

When $\mathrm{E} / E_{\mathrm{k}}=1$, the RLC light level is "optimal" and neither saturating nor limiting. Under limiting light levels (and up to $\mathrm{E} / E_{\mathrm{k}} \sim 0.5$ ), effective photochemical efficiency under actinic light $\left(F_{\mathrm{q}}{ }^{\prime} / F_{\mathrm{m}}{ }^{\prime}\right)$ was between 0.7 and 0.8 , suggesting a 70 $80 \%$ photosynthetic efficiency. When $\mathrm{E} / E_{\mathrm{k}}=1$, despite being theoretically optimal, $F_{\mathrm{q}}{ }^{\prime} / F_{\mathrm{m}}{ }^{\prime}$ and photochemical quenching (qP) had decreased from initial values by $\sim 20-30 \%$ reaching a minimum when RLC light levels were $\sim 10 \times E_{\mathrm{k}}$ (Figure 4). For non-photochemical quenching ( $\mathrm{qN}$ and NPQ), a slight increase began at $\mathrm{E} / E_{\mathrm{k}}=0.1$, rising rapidly at $\mathrm{E} / E_{\mathrm{k}}>1$ and reaching a maximum at $\mathrm{E} / E_{\mathrm{k}}=\sim 10$, although this was characterized by a wide variability (Figure 4). L. digitata tended to have higher $\mathrm{qN}$ and NPQ values across a wider range of $\mathrm{E} / E_{\mathrm{k}}$ (Figure 4).

\section{DISCUSSION}

We examined sub-lethal photophysiological responses of two canopy-forming kelp species to a short-term acute warming event. In terms of net oxygen flux in the light (i.e., net photosynthesis), L. digitata exhibited a significant ecophysiological response, whilst $L$. hyperborea appeared less sensitive with no apparent effect on net photosynthesis. Investigation of the associated photosynthetic characteristics revealed no significant trends in either species as a result of warming, despite the significant increase in net oxygen release in L. digitata. This suggests these kelp species exhibit a degree of photophysiological resilience to short-term acute warming.

TABLE 1 | The effect of temperature treatment, tank and experimental day on net oxygen flux as determined by RM ANOVA for both Laminaria digitata and Laminaria hyperborea.

\begin{tabular}{|c|c|c|c|c|c|c|c|c|c|c|c|}
\hline \multirow[t]{2}{*}{ Spp } & \multicolumn{3}{|c|}{ Temp [2] } & \multirow{2}{*}{$\frac{\text { Tank (Temp) [9] }}{\text { MS }}$} & \multicolumn{3}{|c|}{ Day [2] } & \multicolumn{3}{|c|}{ Temp x Day [4] } & \multirow{2}{*}{$\begin{array}{c}\text { Res [18] } \\
\text { MS }\end{array}$} \\
\hline & MS & $\boldsymbol{F}$ & $P$ & & MS & $\boldsymbol{F}$ & $P$ & MS & $\boldsymbol{F}$ & $P$ & \\
\hline \multirow[t]{2}{*}{ LD } & $7.3 \times 10^{6}$ & 9.73 & 0.006 & $7.6 \times 10^{5}$ & $5.1 \times 10^{6}$ & 4.39 & 0.028 & $1.1 \times 10^{6}$ & 0.97 & 0.446 & $1.2 \times 10^{6}$ \\
\hline & \multicolumn{11}{|c|}{ Pairwise tests; temp: $T_{0}=T_{1}<T_{2}$. Day: $3>1,3=2,2=1$} \\
\hline $\mathrm{LH}$ & $1.6 \times 10^{6}$ & 2.76 & 0.116 & $5.7 \times 10^{5}$ & $7.3 \times 10^{5}$ & 1.89 & 0.109 & $1.4 \times 10^{6}$ & 3.72 & 0.007 & $2.9 \times 10^{5}$ \\
\hline
\end{tabular}

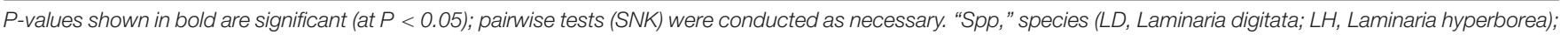
"Res," residual. Degrees of freedom (df) associated with each factor are shown in squared brackets. 

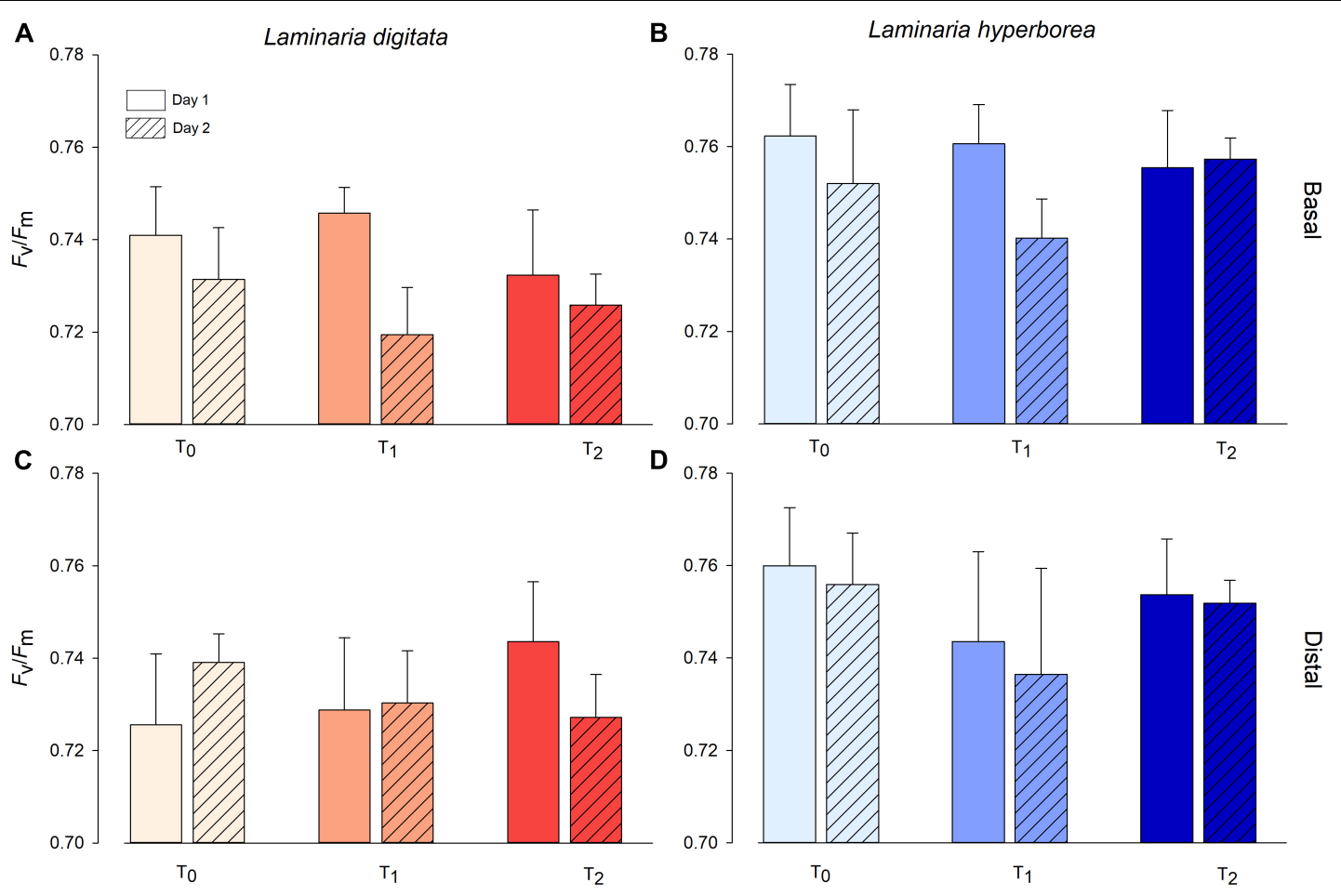

FIGURE 2 | Photosynthetic efficiency $\left(F_{\mathrm{v}} / F_{\mathrm{m}}\right)$ of $L$. digitata $(\mathbf{A}, \mathbf{C})$ and $L$. hyperborea $(\mathbf{B}, \mathbf{D})$ at the distal and basal sections of blade tissue under each temperature treatment on days 1 and 2 of the simulated heat spike event, as measured via PAM fluorometry. Data presented as mean \pm SE $(n=4$ individual aquaria per treatment).

TABLE 2 | The effect of temperature treatment, tank and experimental day on $F_{\mathrm{v}} / F_{\mathrm{m}}$ and $E_{\mathrm{k}}$, as determined by RM ANOVA for Laminaria digitata and Laminaria hyperborea for both basal and distal blade tissue.

\begin{tabular}{|c|c|c|c|c|c|c|c|c|c|c|c|c|c|}
\hline \multirow[t]{2}{*}{ Spp } & \multirow[t]{2}{*}{ Var } & \multirow[t]{2}{*}{ Sect } & \multicolumn{3}{|c|}{ Temp [2] } & \multirow{2}{*}{$\frac{\text { Tank (Temp) [9] }}{\text { MS }}$} & \multicolumn{3}{|c|}{ Day [1] } & \multicolumn{3}{|c|}{ Temp x Day [2] } & \multirow{2}{*}{$\begin{array}{c}\text { Res [9] } \\
\text { MS }\end{array}$} \\
\hline & & & MS & $\boldsymbol{F}$ & $P$ & & MS & $\boldsymbol{F}$ & $P$ & MS & $\boldsymbol{F}$ & $P$ & \\
\hline \multirow[t]{6}{*}{ LD } & $F_{\mathrm{v}} / F_{\mathrm{m}}$ & Basal & $9.0 \times 1^{-5}$ & 0.54 & 0.599 & $1.7 \times 10^{-4}$ & $1.2 \times 10^{-3}$ & 15.07 & 0.004 & $2.2 \times 10^{-4}$ & 2.79 & 0.114 & $8.0 \times 10^{-5}$ \\
\hline & & Distal & $5.0 \times 10^{-5}$ & 0.19 & 0.834 & $2.8 \times 10^{-4}$ & $3.7 \times 10^{-7}$ & 0.01 & 0.969 & $3.0 \times 10^{-4}$ & 1.28 & 0.323 & $2.3 \times 10^{-4}$ \\
\hline & $E_{\mathrm{k}}$ & Basal & 118.3 & 1.26 & 0.327 & 93.2 & 954.7 & 17.61 & 0.002 & 21.0 & 0.38 & 0.689 & 54.2 \\
\hline & & Distal & 199.1 & 1.63 & 0.248 & 121.9 & 104.6 & 2.63 & 0.139 & 118.8 & 2.99 & 0.101 & 39.6 \\
\hline & Pairwis & sts: $F_{\mathrm{V}}$ & basal; Day: & 2 & & & & & & & & & \\
\hline & $E_{\mathrm{k}}$ bas & Day: 1 & & & & & & & & & & & \\
\hline \multirow[t]{4}{*}{$\mathrm{LH}$} & $F_{\mathrm{v}} / F_{\mathrm{m}}$ & Basal & $1.1 \times 10^{-4}$ & 0.31 & 0.741 & $3.7 \times 10^{-4}$ & $4.2 \times 10^{-4}$ & 3.00 & 0.117 & $3.4 \times 10^{-4}$ & 2.38 & 0.147 & $4.2 \times 10^{-4}$ \\
\hline & & Distal & $6.8 \times 10^{-4}$ & 2.46 & 0.140 & $2.7 \times 10^{-4}$ & $1.1 \times 10^{-4}$ & 0.23 & 0.644 & $1.3 \times 10^{-5}$ & 0.02 & 0.973 & $4.9 \times 10^{-4}$ \\
\hline & $E_{\mathrm{k}}$ & Basal & 108.5 & 0.87 & 0.452 & 124.7 & 18.9 & 0.51 & 0.492 & 2.7 & 0.07 & 0.929 & 36.9 \\
\hline & & Distal & 490.0 & 3.42 & 0.078 & 143.2 & 1036.7 & 39.48 & 0.001 & 72.3 & 2.75 & 0.117 & 160.2 \\
\hline
\end{tabular}

Pairwise tests: $E_{\mathrm{k}}$ distal; Day: $1>2$

P-values shown in bold are significant (at P < 0.05); pairwise tests (SNK) were conducted as necessary. "Spp," species (LD, Laminaria digitata; LH, Laminaria hyperborea); "Var," response variable; "Sect," section; "Res," residual. Degrees of freedom (df) associated with each factor are shown in squared brackets.

\section{Temperature Responses}

Up to a certain threshold, increasing temperature is expected to increase macroalgal oxygen production, due to higher electron transport rate through the photosystems (Delebecq et al., 2016). This trend was clearly observed for L. digitata, even after just 3 days of acute exposure to the high-magnitude $T_{2}$ warming treatment. Chronic, longer-term exposure to the absolute temperatures used here for the warming treatments (i.e., $\sim 18-20^{\circ} \mathrm{C}$ ) is known to result in reduced ecophysiological performance (Simonson et al., 2015; Hargrave et al., 2017), increased mortality (Bartsch et al., 2013; Wilson et al., 2015), and consequent population-level impacts (Raybaud et al., 2013) for $L$. digitata, reinforcing the sensitivity of this species to elevated temperature. In contrast to $L$. digitata, a consistent oxygen production response was not observed in L. hyperborea, suggesting a degree of variability and/or insensitivity to 

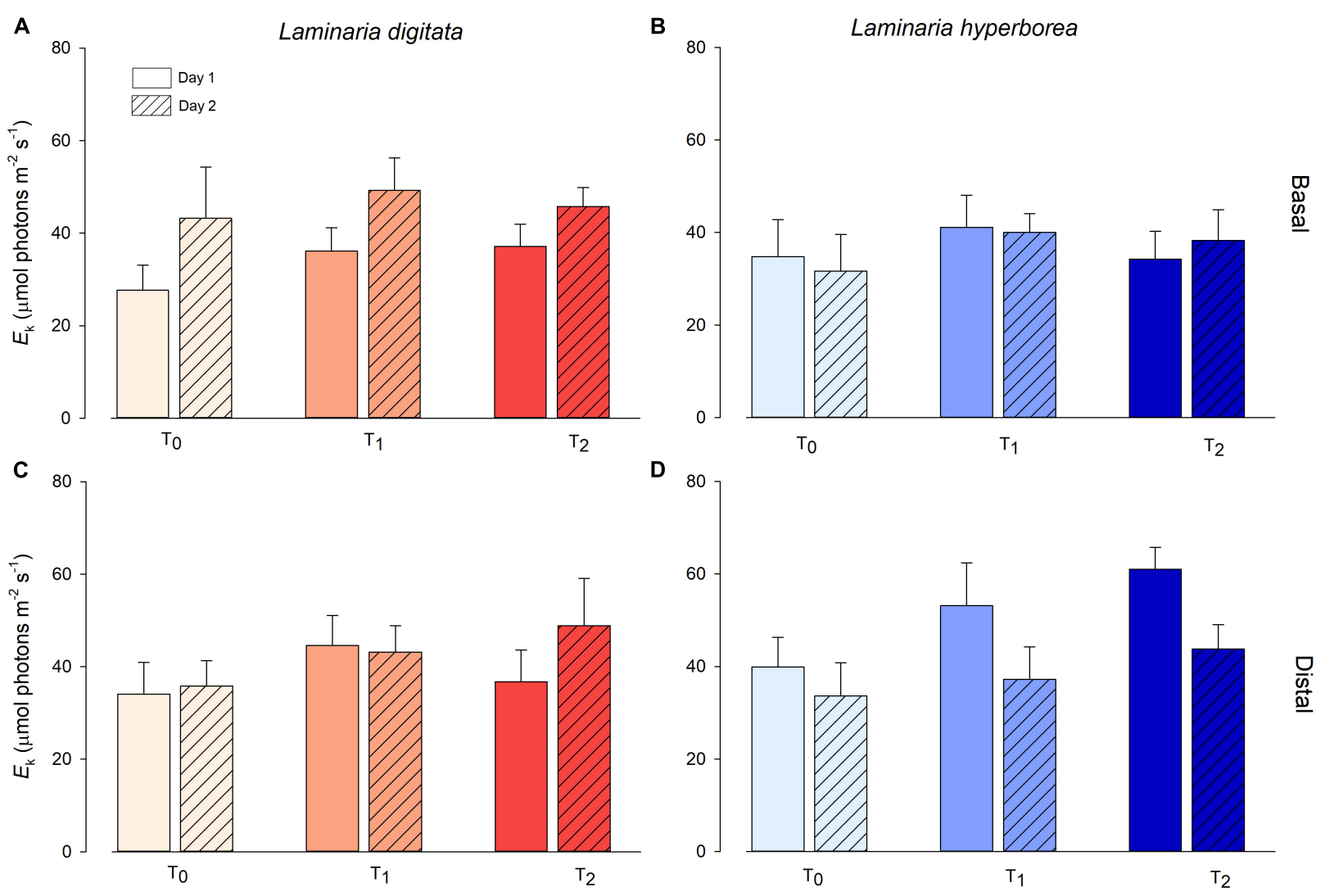

FIGURE 3 | Minimum saturation intensity $\left(E_{k}, \mu\right.$ mol photons $\left.\mathrm{m}^{-2} \mathrm{~s}^{-1}\right)$ of $L$. digitata $(\mathbf{A}, \mathbf{C})$ and $L$. hyperborea (B,D) at the distal and basal sections of blade tissue under each temperature treatment on days 1 and 2 of the simulated heat spike event, as measured via PAM fluorometry. Data presented as mean \pm SE $(n=4$ individual aquaria per treatment).

the temperature increases tested in this study. Oxygen flux measurements are only available in the light, preventing an assessment of net respiration rates. While this limits the extent of physiological insight, it does not diminish the significant trends in daytime net oxygen flux under simulated warming event. In the field, this physiological response could have significant biogeochemical implications since macrophytic photosynthesis is also major driver of daytime oxygen elevation in coastal systems (Burdett et al., 2013; Attard et al., 2015). In the absence of dark net respiration rates it is not yet possible to determine the full effect a warming event might have on the magnitude of diel oxygen variation. Interestingly, despite a significant response in net daytime oxygen production, no significant response in photosynthetic characteristics were observed in either species, suggesting that during acute, short-term warming events core photophysiological processes can be maintained with only a physiological response. Trends in $F_{\mathrm{v}} / F_{\mathrm{m}}, E_{\mathrm{k}}$ and $\mathrm{rETR}_{\max }$ suggest that increased temperature may have increased the electron transport rate through photosystem II and reduced photosynthetic, but not to such an extent as to be beyond the natural between-plant variability and temperature-driven increase in oxygen-flux kinetics.

The insensitivity of photosynthetic characteristics to elevated temperature allows us to compare the two species responses.
Via an elevated and more light-responsive non-photochemical quenching response (an effective method for dissipating excess absorbed energy), L. digitata may have a greater potential capacity for photo-protection. This was driven by an elevated maximal fluorescence $\left(F_{\mathrm{m}}{ }^{\prime}\right)$ - which can also correspond to an up-regulation of photo-protective xanthophyll cycling (Lavaud et al., 2002). Further pigment-level analyses would be required to confirm this mechanism. For L. digitata, experimental day also had an effect on the photosynthetic characteristics of the basal tissue. The meristoderm of kelps (the peripheral layer of photosynthetically active cells of the basal tissue) is known to be highly biogeochemically active and capable of accumulating significant iodine concentrations (Küpper and Carrano, 2019). Such biogeochemical activity may increase the sensitivity of this tissue to altered environmental conditions (whether via experimental treatment or laboratory conditions) leading to the integrated observational response seen in this study.

\section{Ecological Implications}

Laminaria digitata and Laminaria hyperborea are critical components of coastal marine ecosystems in the NE Atlantic, as they provide complex habitat for a wide range of associated flora and fauna (Blight and Thompson, 2008; Schaal et al., 2016; Teagle et al., 2018) and exhibit high rates of carbon 

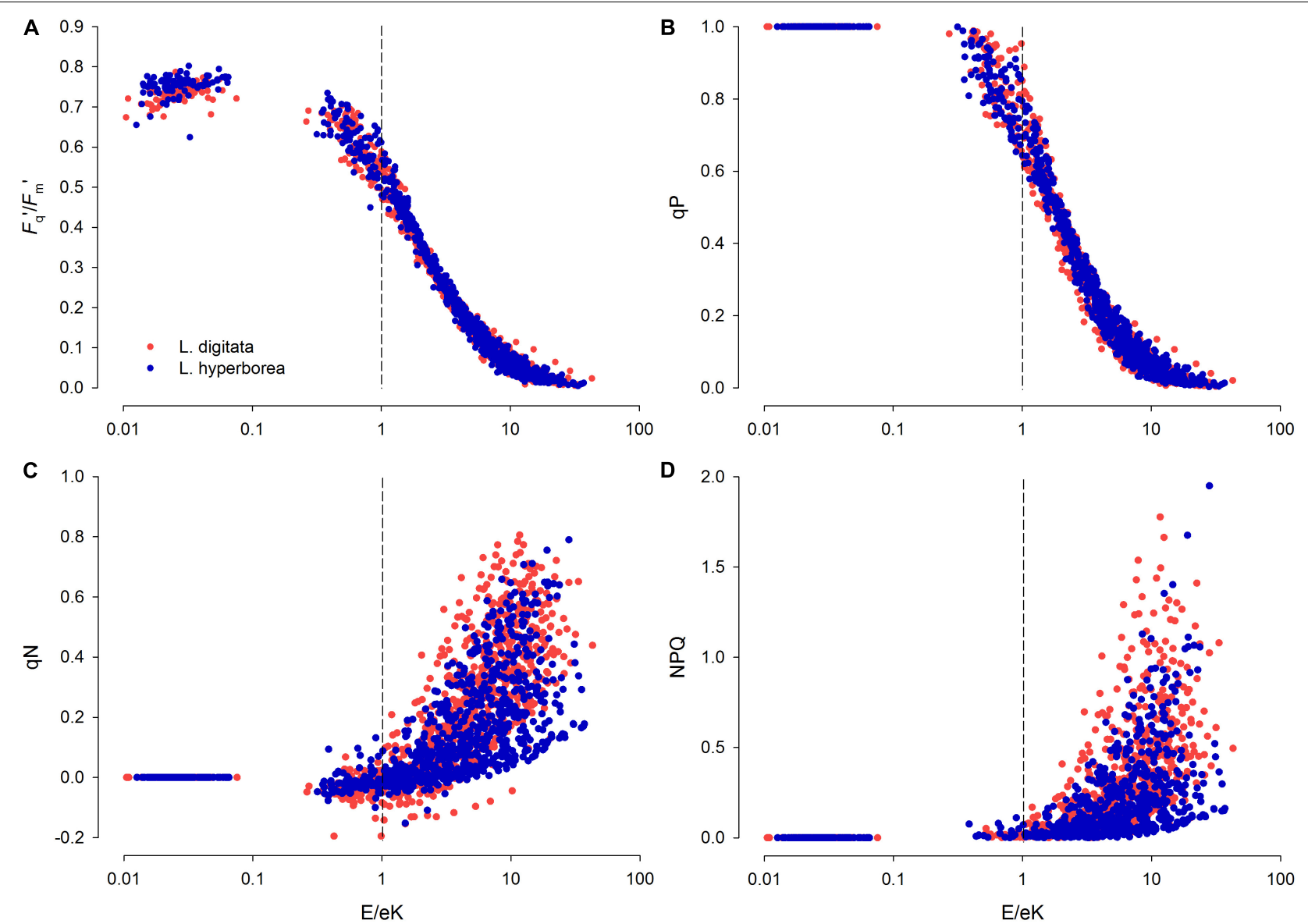

FIGURE $4 \mid E / E_{\mathrm{k}}$ against (A) light-acclimated photosynthetic yield $\left(F_{\mathrm{q}}{ }^{\prime} / F_{\mathrm{m}}{ }^{\prime}\right)$, (B) photochemical quenching $(\mathrm{qP})$, and (C,D) non-photochemical quenching $(\mathrm{qN}$ and $N P Q$, respectively) for $L$. digitata (red circles) and $L$. hyperborea (blue circles), obtained from results from each step of the rapid light curve ( $n=768$ data points per species - data pooled across treatments). E, Rapid Light Curve step intensity [photosynthetically active radiation (PAR), $\mu$ mol photons $\mathrm{m}^{-2} \mathrm{~s}^{-1}$ ] and $E_{\mathrm{k}}$, minimum saturation intensity ( $\mu \mathrm{mol}$ photons $\mathrm{m}^{-2} \mathrm{~s}^{-1}$ ), calculated from the RLC data. At $E / E_{\mathrm{k}}=1$ (vertical dashed line), light level is optimal for photosynthetic efficiency (i.e., neither limiting nor saturating).

capture and release (Schaal et al., 2009; Hereward et al., 2018; Pessarrodona et al., 2018). Recent and projected warming trends have been linked with population losses and range contractions at the equatorward limit of the distributions of both L. digitata (Raybaud et al., 2013) and L. hyperborea (Voerman et al., 2013; Casado-Amezúa et al., 2019) in France and Spain/Portugal, respectively. Prolonged exposure to warmerthan-average sea temperatures can manifest in responses at the organism level, such as decreased growth (Hargrave et al., 2017), and at the population level, such as reproductive failure (Bartsch et al., 2013). Similarly, exposure to acute air temperature stress during periods of low-tide emersion can have impacts at the physiological and individual level (King et al., 2018b). Ultimately, warming can lead to the loss of kelp populations at the range edge, with subsequent shifts in the structure of communities (Voerman et al., 2013) and even ecosystems (Wernberg et al., 2016).

The scale of the heating spike simulated in this study (in terms of duration and magnitude) is frequently observed in the study region, which experiences short-term temperature variability as well as longer-lasting MHW events (Joint and Smale, 2017; Brewin et al., 2018). Both species exhibited photophysiological resilience to an acute period of high temperature; short-lived warming events may therefore not physiologically impact these kelp species. The significant increase in net daytime oxygen flux by $L$. digitata suggests that this species has a lower sensitivity threshold, perhaps because it is near the southerly range edge of its distribution, and already under physiological pressure. It is likely that increased exposure to acute warming events (whether seawater or air temperatures) combined with longerterm exposure to gradual increases in mean sea temperature, will negatively impact range edge populations, leading to shifts in the species distribution and altered community structure (Raybaud et al., 2013; Filbee-Dexter et al., 2016). However, it should be noted that this study was conducted on single populations over a single event and did not account for any local adaptation that could lead to between-population variability in thermal tolerance. Indeed, thermal divergence between populations has been shown for several kelp species (Gerard and Du Bois, 1988; King et al., 2019) and may be commonplace in marine macrophyte 
species more generally (King et al., 2018a). Clearly, further work comparing photophysiological responses to temperature across multiple populations within these species' ranges and in response to varied temperature regimes is needed to confirm the photophysiological resilience of these species to the chronic and acute ocean warming projected for the coming decades. Recent advances in situ experimentation via manipulation of environmental conditions within an incubation chamber (e.g., Gattuso et al., 2014; Burdett et al., 2018) provide the opportunity to conduct comparable experiments with reduced laboratory artifacts and the capacity to investigate these questions at the organism to community scale.

Canopy-forming kelp species are vital components of mid and high-latitude coastal ecosystems, underpinning core ecological processes such as primary productivity, trophic connectivity and habitat provision (Blight and Thompson, 2008; Smale et al., 2013). As macroalgal species' distributions are strongly constrained by temperature, recent warming trends have driven shifts in their geographical ranges (e.g., Raybaud et al., 2013; Schaal et al., 2016; Pessarrodona et al., 2018) and projected warming will continue drive changes in the coming decades (Müller et al., 2009; Hereward et al., 2018). MHW events further compound decadal-scale ocean warming by exerting acute and intense stress onto organisms, populations, communities, and ecosystems. Projected increases in $\mathrm{MHW}$ activity in coming decades (Frölicher et al., 2018) will likely coincide with current kelp population distributions. This study suggests that those populations near their upper thermal limit may be most affected (i.e., equator range edge - L. digitata in this study) because of a slight increase in photophysiological sensitivity. Prolonged or repeated responses in terms of net oxygen production may provide short-term metabolic benefits in some species (via increased oxygen production), but also increased energy use and

\section{REFERENCES}

Attard, K., Stahl, H., Kamenos, N., Turner, G., Burdett, H., and Glud, R. (2015). Benthic oxygen exchange in a live coralline algal bed and an adjacent sandy habitat: an eddy covariance study. Mar. Ecol. Prog. Ser. 535, 99-115. doi: 10.3354/meps11413

Bartsch, I., Vogt, J., Pehlke, C., and Hanelt, D. (2013). Prevailing sea surface temperatures inhibit summer reproduction of the kelp Laminaria digitata at Helgoland (North Sea). J. Phycol. 49, 1061-1073. doi: 10.1111/jpy. 12125

Bilger, W., and Björkman, O. (1990). Role of the xanthophyll cycle in photoprotection elucidated by measurements of light-induced absorbance changes, fluorescence and photosynthesis in leaves of Hedera canariensis. Photosynth. Res. 25, 173-185. doi: 10.1007/BF00033159

Blight, A., and Thompson, R. (2008). Epibiont species richness varies between holdfasts of a northern and a southerly distributed kelp species. J. Mar. Biol. Assoc. U.K. 88, 469-475. doi: 10.1017/s0025315408000994

Bolton, J., and Lüning, K. (1982). Optimal growth and maximal survival temperatures of Atlantic Laminaria species (Phaeophyta) in culture. Mar. Biol. 66, 89-94. doi: 10.1007/bf00397259

Bolton, J. J. (2010). The biogeography of kelps (Laminariales, Phaeophyceae): a global analysis with new insights from recent advances in molecular phylogenetics. Helgol. Mar. Res. 64, 263-279. doi: 10.1007/s10152-0100211-6

Brewin, R., Smale, D., Moore, P., Dall'olmo, G., Miller, P., Taylor, B., et al. (2018). Evaluating operational AVHRR sea surface temperature data at the demand in the longer term. A deeper mechanistic understanding of ecophysiological responses to increased temperature is needed to better predict near-future impacts of ocean warming on kelp populations and communities.

\section{DATA AVAILABILITY}

All datasets generated for this study are included in the manuscript and/or the Supplementary Files.

\section{AUTHOR CONTRIBUTIONS}

$\mathrm{HB}$ and DS co-designed the experiment and analyzed the data. All authors performed the experiment, took the samples, made measurements, and wrote the manuscript.

\section{FUNDING}

This research was supported by a Marine Biological Association Ray Lankester Investigatorship awarded to HB and was conducted whilst DS was in receipt of a Natural Environmental Research Council Independent Research Fellowship (NE/K008439/1).

\section{SUPPLEMENTARY MATERIAL}

The Supplementary Material for this article can be found online at: https://www.frontiersin.org/articles/10.3389/fmars. 2019.00516/full\#supplementary-material

coastline using benthic temperature loggers. Remote Sens. 10:925. doi: 10.3390/ rs10060925

Brewin, R. J., De Mora, L., Billson, O., Jackson, T., Russell, P., Brewin, T. G., et al. (2017). Evaluating operational AVHRR sea surface temperature data at the coastline using surfers. Estuar. Coast. Shelf Sci. 196, 276-289. doi: 10.1016/ j.ecss.2017.07.011

Brodie, J., Williamson, C. J., Smale, D. A., Kamenos, N. A., Mieszkowska, N., Santos, R., et al. (2014). The future of the northeast Atlantic benthic flora in a high $\mathrm{CO}_{2}$ world. Ecol. Evol. 4, 2787-2798. doi: 10.1002/ece3.1105

Burdett, H. L., Carruthers, M., Donohue, P. J. C., Wicks, L. C., Hennige, S. J., Roberts, J. M., et al. (2014). Effects of high temperature and $\mathrm{CO}_{2}$ on intracellular DMSP in the cold-water coral Lophelia pertusa. Mar. Biol. 161, 1499-1506. doi: 10.1007/s00227-014-2435-5

Burdett, H. L., Donohue, P. J. C., Hatton, A. D., Alwany, M. A., and Kamenos, N. A. (2013). Spatiotemporal variability of dimethylsulphoniopropionate on a fringing coral reef: the role of reefal carbonate chemistry and environmental variability. PLoS One 8:e64651. doi: 10.1371/journal.pone.006 4651

Burdett, H. L., Hennige, S. J., Francis, F. T.-Y., and Kamenos, N. A. (2012). The photosynthetic characteristics of red coralline algae, determined using pulse amplitude modulation (PAM) fluorometry. Botanica Marina 55, 499-509.

Burdett, H. L., Perna, G., Mckay, L., Broomhead, G., and Kamenos, N. A. (2018). Community-level sensitivity of a calcifying ecosystem to acute in situ $\mathrm{CO}_{2}$ enrichment. Mar. Ecol. Prog. Ser. 587, 73-80. doi: 10.3354/meps12421

Casado-Amezúa, P., Araújo, R., Bárbara, I., Bermejo, R., Borja, Á, Díez, I., et al. (2019). Distributional shifts of canopy-forming seaweeds from the Atlantic 
coast of Southern Europe. Biodivers. Conserv. 28, 1151-1172. doi: 10.1007/ s10531-019-01716-9

Delebecq, G., Davoult, D., Janquin, M.-A., Oppliger, L. V., Menu, D., Dauvin, J.C., et al. (2016). Photosynthetic response to light and temperature in Laminaria digitata gametophytes from two French populations. Eur. J. Phycol. 51, 71-82. doi: 10.1080/09670262.2015.1104556

Eggert, A. (2012). “Seaweed Responses to Temperature," in Seaweed Biology. Berlin: Springer, 47-66.

Filbee-Dexter, K., Feehan, C. J., and Scheibling, R. E. (2016). Large-scale degradation of a kelp ecosystem in an ocean warming hotspot. Mar. Ecol. Prog. Ser. 543, 141-152. doi: 10.3354/meps 11554

Frölicher, T. L., Fischer, E. M., and Gruber, N. (2018). Marine heatwaves under global warming. Nature 560, 360-364. doi: 10.1038/s41586-018-0383-9

García Molinos, J., Halpern, B. S., Schoeman, D. S., Brown, C. J., Kiessling, W., Moore, P. J., et al. (2016). Climate velocity and the future global redistribution of marine biodiversity. Nat. Clim. Change 6, 83-88. doi: 10.1111/gcb.12726

Gattuso, J. P., Kirkwood, W., Barry, J. P., Cox, E., Gazeau, F., Hansson, L., et al. (2014). Free-ocean $\mathrm{CO}_{2}$ enrichment (FOCE) systems: present status and future developments. Biogeosciences 11, 4057-4075. doi: 10.5194/bg-11-4057-2014

Gerard, V., and Du Bois, K. (1988). Temperature ecotypes near the southern boundary of the kelp Laminaria saccharina. Mar. Biol. 97, 575-580. doi: 10 . 1007/bf00391054

Gouvêa, L. P., Schubert, N., Martins, C. D. L., Sissini, M., Ramlov, F., Rodrigues, E. R. D. O., et al. (2017). Interactive effects of marine heatwaves and eutrophication on the ecophysiology of a widespread and ecologically important macroalga. Limnol. Oceanogr. 62, 2056-2075. doi: 10.1002/lno. 10551

Hargrave, M. S., Foggo, A., Pessarrodona, A., and Smale, D. A. (2017). The effects of warming on the ecophysiology of two co-existing kelp species with contrasting distributions. Oecologia 183, 531-543. doi: 10.1007/s00442-0163776-1

Harley, C. D., Anderson, K. M., Demes, K. W., Jorve, J. P., Kordas, R. L., Coyle, T. A., et al. (2012). Effects of climate change on global seaweed communities. J. Phycol. 48, 1064-1078. doi: 10.1111/j.1529-8817.2012.01224.x

Hennige, S., Smith, D., Perkins, R., Consalvey, M., Paterson, D., and Suggett, D. (2008). Photoacclimation, growth and distribution of massive coral species in clear and turbid waters. Mar. Ecol. Prog. Ser. 369, 77-88. doi: 10.3354/ meps07612

Hereward, H. F., Foggo, A., Hinckley, S. L., Greenwood, J., and Smale, D. A. (2018). Seasonal variability in the population structure of a habitat-forming kelp and a conspicuous gastropod grazer: do blue-rayed limpets (Patella pellucida) exert top-down pressure on Laminaria digitata populations? J. Exp. Mar. Biol. Ecol. 506, 171-181. doi: 10.1016/j.jembe.2018.06.011

Hobday, A. J., Alexander, L. V., Perkins, S. E., Smale, D. A., Straub, S. C., Oliver, E. C., et al. (2016). A hierarchical approach to defining marine heatwaves. Prog. Oceanogr. 141, 227-238. doi: 10.1016/j.pocean.2015.12.014

Hobday, A. J., Oliver, E., Sen Gupta, A., Benthuysen, J. A., Burrows, M. T., Donat, M. G., et al. (2018). Categorizing and naming marine heatwaves. Oceanography $31,1-13$.

Hughes, T. P., Barnes, M. L., Bellwood, D. R., Cinner, J. E., Cumming, G. S., Jackson, J. B. C., et al. (2017). Coral reefs in the anthropocene. Nature 546, 82-90.

IPCC. (2013). “Climate Change 2013,” in The Physical Science Basis. Contribution of Working Group I to the Fifth Assessment Report of the Intergovernmental Panel on Climate Change, eds T. F. Stocker, D. Qin, G.-K. Plattner, M. Tignor, S. K. Allen, J. Boschung, et al. (Cambridge: Cambridge University Press).

Jassby, A. D., and Platt, T. (1976). Mathematical formulation of the relationship between photosynthesis and light for phytoplankton. Limnol. Oceanogr. 21, 540-547. doi: 10.4319/lo.1976.21.4.0540

Joint, I., and Smale, D. A. (2017). Marine heatwaves and optimal temperatures for microbial assemblage activity. FEMS Microbiol. Ecol. 93:fiw243. doi: 10.1093/ femsec/fiw243

King, N. G., Mckeown, N. J., Smale, D. A., and Moore, P. J. (2018a). The importance of phenotypic plasticity and local adaptation in driving intraspecific variability in thermal niches of marine macrophytes. Ecography 41, 1469-1484. doi: 10 . 1111/ecog.03186

King, N. G., Mckeown, N. J., Smale, D. A., Wilcockson, D. C., Hoelters, L., Groves, E. A., et al. (2019). Evidence for different thermal ecotypes in range centre and trailing edge kelp populations. J. Exp. Mar. Biol. Ecol. 514, 10-17. doi: 10.1016/j.jembe.2019.03.004

King, N. G., Wilcockson, D. C., Webster, R., Smale, D. A., Hoelters, L. S., and Moore, P. J. (2018b). Cumulative stress restricts niche filling potential of habitat-forming kelps in a future climate. Funct. Ecol. 32, 288-299. doi: 10.1111/ 1365-2435.12977

Krause-Jensen, D., and Duarte, C. M. (2016). Substantial role of macroalgae in marine carbon sequestration. Nat. Geosci. 9, 737-742. doi: 10.1007/s13280-0160849-7

Krumhansl, K. A., Okamoto, D. K., Rassweiler, A., Novak, M., Bolton, J. J., Cavanaugh, K. C., et al. (2016). Global patterns of kelp forest change over the past half-century. Proc. Natl. Acad. Sci. U.S.A. 113, 13785-13790.

Küpper, F. C., and Carrano, C. J. (2019). Key aspects of the iodine metabolism in brown algae: a brief critical review. Metallomics 11, 756-764. doi: 10.1039/ c8mt00327k

Lavaud, J., Rousseau, B., Van Gorkom, H. J., and Etienne, A.-L. (2002). Influence of the diadinoxanthin pool size on photoprotection in the marine planktonic diatom Phaeodactylum tricornutum. Plant Physiol. 129, 1398-1406. doi: 10. 1104/pp.002014

Müller, R., Laepple, T., Bartsch, I., and Wiencke, C. (2009). Impact of oceanic warming on the distribution of seaweeds in polar and cold-temperate waters. Botanica Marina 52, 617-638.

Oliver, E., Donat, M. G., Burrows, M. T., Moore, P. J., Smale, D. A., Alexander, L. V., et al. (2018). Longer and more frequent marine heatwaves over the past century. Nat. Commun. 9:1324. doi: 10.1038/s41467-018-03732-9

Pecl, G. T., Araújo, M. B., Bell, J. D., Blanchard, J., Bonebrake, T. C., Chen, I.C., et al. (2017). Biodiversity redistribution under climate change: impacts on ecosystems and human well-being. Science 355:eaai9214. doi: 10.1126/science. aai9214

Pedersen, M. F., Nejrup, L. B., Pedersen, T. M., and Fredriksen, S. (2014). Subcanopy light conditions only allow low annual net productivity of epiphytic algae on kelp Laminaria hyperborea. Mar. Ecol. Prog. Ser. 516, 163-176. doi: 10.3354/meps11019

Pessarrodona, A., Foggo, A., and Smale, D. A. (2019). Can ecosystem functioning be maintained despite climate-driven shifts in species composition? Insights from novel marine forests. J. Ecol. 107, 91-104. doi: 10.1111/1365-2745.13053

Pessarrodona, A., Moore, P. J., Sayer, M. D., and Smale, D. A. (2018). Carbon assimilation and transfer through kelp forests in the NE Atlantic is diminished under a warmer ocean climate. Glob. Change Biol. 24, 4386-4398. doi: 10.1111/ gcb.14303

Pinsky, M. L., Worm, B., Fogarty, M. J., Sarmiento, J. L., and Levin, S. A. (2013). Marine taxa track local climate velocities. Science 341, 1239-1242. doi: 10.1126/ science. 1239352

Poloczanska, E. S., Brown, C. J., Sydeman, W. J., Kiessling, W., Schoeman, D. S., Moore, P. J., et al. (2013). Global imprint of climate change on marine life. Nat. Clim. Change 3, 919-925. doi: 10.1038/nclimate1958

Ralph, P. J., and Gademann, R. (2005). Rapid light curves: a powerful tool to assess photosynthetic activity. Aquat. Bot. 82, 222-237. doi: 10.1016/j.aquabot.2005. 02.006

Raybaud, V., Beaugrand, G., Goberville, E., Delebecq, G., Destombe, C., Valero, M., et al. (2013). Decline in kelp in west Europe and climate. PLoS One 8:e66044. doi: 10.1371/journal.pone.0066044

Schaal, G., Leclerc, J.-C., Droual, G., Leroux, C., and Riera, P. (2016). Biodiversity and trophic structure of invertebrate assemblages associated with understorey red algae in a Laminaria digitata bed. Mar. Biol. Res. 12, 513-523. doi: 10.1080/ 17451000.2016.1164318

Schaal, G., Riera, P., and Leroux, C. (2009). Trophic significance of the kelp Laminaria digitata (Lamour.) for the associated food web: a between-sites comparison. Estuar. Coast Shelf Sci. 85, 565-572. doi: 10.1016/j.ecss.2009. 09.027

Silsbe, G., and Malkin, S. (2015). phytotools: Phytoplankton Production Tools [Online]. Available: https://cran.r-project.org/web/packages/phytotools/index. html (accessed February 2, 2019).

Simonson, E., Scheibling, R., and Metaxas, A. (2015). Kelp in hot water: I. Warming seawater temperature induces weakening and loss of kelp tissue. Mar. Ecol. Prog. Ser. 537, 89-104. doi: 10.3354/meps 11438

Smale, D. A., Burrows, M. T., Evans, A. J., King, N., Sayer, M. D. J., Yunnie, A. L. E., et al. (2016). Linking environmental variables with regional- scale variability in 
ecological structure and standing stock of carbon within UK kelp forests. Mar. Ecol. Prog. Ser. 542, 79-95. doi: 10.3354/meps11544

Smale, D. A., Burrows, M. T., Moore, P., O'connor, N., and Hawkins, S. J. (2013). Threats and knowledge gaps for ecosystem services provided by kelp forests: a northeast Atlantic perspective. Ecol. Evol. 3, 4016-4038. doi: 10.1002/ece3.774

Smale, D. A., Moore, P. J., Queirós, A. M., Higgs, N. D., and Burrows, M. T. (2018). Appreciating interconnectivity between habitats is key to blue carbon management. Front. Ecol. Environ. 16:71-73. doi: 10.1002/fee.1765

Smale, D. A., Wernberg, T., Yunnie, A. L. E., and Vance, T. (2015). The rise of Laminaria ochroleuca in the Western English Channel (UK) and comparisons with its competitor and assemblage dominant Laminaria hyperborea. Mar. Ecol. 36, 1033-1044. doi: 10.1111/maec.12199

Smyth, T. J., Fishwick, J. R., Al-Moosawi, L., Cummings, D. G., Harris, C., Kitidis, V., et al. (2009). A broad spatio-temporal view of the Western English Channel observatory. J. Plankton Res. 32, 585-601. doi: 10.1093/plankt/ fbp 128

Steneck, R. S., Graham, M. H., Bourque, B. J., Corbett, D., Erlandson, J. M., Estes, J. A., et al. (2002). Kelp forest ecosystems: biodiversity, stability, resilience and future. Environ. Conserv. 29, 436-459. doi: 10.1017/s03768929020 00322

Steneck, R. S., and Johnson, C. R. (2013). "Kelp forests: dynamic patterns, processes and feedbacks," in Marine Community Ecology, eds M. D. Bertness, B. Silliman, and J. Stachowitz (Sunderland, MA:: Sinauer), 315-336.

Sunday, J. M., Bates, A. E., and Dulvy, N. K. (2012). Thermal tolerance and the global redistribution of animals. Nat. Clim. Change 2, 686-690. doi: 10.1038/ nclimate1539

Teagle, H., Hawkins, S. J., Moore, P. J., and Smale, D. A. (2017). The role of kelp species as biogenic habitat formers in coastal marine ecosystems. J. Exp. Mar. Biol. Ecol. 492, 81-98. doi: 10.1371/journal.pone.0200411

Teagle, H., Moore, P. J., Jenkins, H., and Smale, D. A. (2018). Spatial variability in the diversity and structure of faunal assemblages associated with kelp holdfasts (Laminaria hyperborea) in the northeast Atlantic. PLoS One 13:e200411. doi: 10.1371/journal.pone.0200411

Teagle, H., and Smale, D. A. (2018). Climate-driven substitution of habitat-forming species leads to reduced biodiversity within a temperate marine community. Divers. Distrib. 24, 1367-1380. doi: 10.1111/ddi.12775 tom Dieck, I. (1993). Temperature tolerance and survival in darkness of kelp gametophytes (Laminariales, Phaeophyta): ecological and biogeographical implications. Mar. Ecol. Prog. Ser. 100, 253-253.

Tuya, F., Png-Gonzalez, L., Riera, R., Haroun, R., and Espino, F. (2014). Ecological structure and function differs between habitats dominated by seagrasses and green seaweeds. Mar. Environ. Res. 98, 1-13. doi: 10.1016/j.marenvres.2014.03.015

Vergés, A., Steinberg, P. D., Hay, M. E., Poore, A. G. B., Campbell, A. H., Ballesteros, E., et al. (2014). The tropicalization of temperate marine ecosystems: climate-mediated changes in herbivory and community phase shifts. Proc. Roy. Soc. B Biol. Sci. 281:20140846. doi: 10.1098/rspb.2014.0846

Voerman, S. E., Llera, E., and Rico, J. M. (2013). Climate driven changes in subtidal kelp forest communities in NW Spain. Mar. Environ. Res. 90, 119-127. doi: 10.1016/j.marenvres.2013.06.006

Wernberg, T., Bennett, S., Babcock, R. C., De Bettignies, T., Cure, K., Depczynski, M., et al. (2016). Climate-driven regime shift of a temperate marine ecosystem. Science 353, 169-172. doi: 10.1126/science.aad8745

Wernberg, T., Smale, D. A., Tuya, F., Thomsen, M. S., Langlois, T. J., De Bettignies, T., et al. (2013). An extreme climatic event alters marine ecosystem structure in a global biodiversity hotspot. Nat. Clim. Change 3, 78-82. doi: 10.1038/ nclimate1627

Wilson, K. L., Kay, L. M., Schmidt, A. L., and Lotze, H. K. (2015). Effects of increasing water temperatures on survival and growth of ecologically and economically important seaweeds in Atlantic Canada: implications for climate change. Mar. Biol. 162, 2431-2444. doi: 10.1007/s00227-015-2769-7

Conflict of Interest Statement: The authors declare that the research was conducted in the absence of any commercial or financial relationships that could be construed as a potential conflict of interest.

Copyright (c) 2019 Burdett, Wright and Smale. This is an open-access article distributed under the terms of the Creative Commons Attribution License (CC BY). The use, distribution or reproduction in other forums is permitted, provided the original author(s) and the copyright owner(s) are credited and that the original publication in this journal is cited, in accordance with accepted academic practice. No use, distribution or reproduction is permitted which does not comply with these terms. 